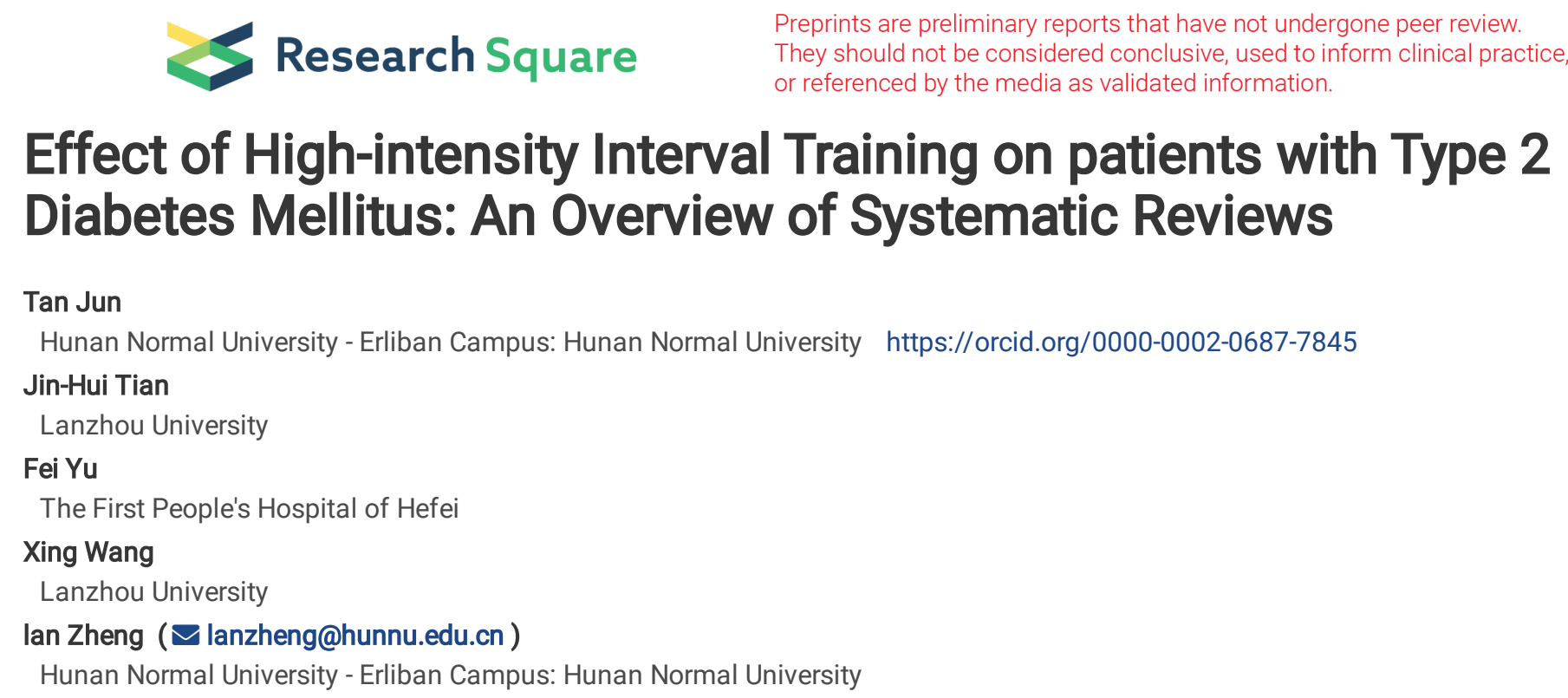

\section{Effect of High-intensity Interval Training on patients with Type 2 Diabetes Mellitus: An Overview of Systematic Reviews}

\title{
Research
}

Keywords: Diabetes Mellitus, Type 2, High-Intensity Interval Training, Systematic Review, Meta-Analysis

Posted Date: June 17th, 2021

DOI: https://doi.org/10.21203/rs.3.rs-457587/v1

License: () (i) This work is licensed under a Creative Commons Attribution 4.0 International License. Read Full License 


\section{Abstract}

\section{Background}

Type 2 Diabetes Mellitus (T2DM) is a serious disease. The intervention of High Intensity Interval Training (HIIT) on T2DM is widely concerned but controversial, which also exists in the current Systematic Reviews/Meta-Analysis (SRs/MAs). The objective of this study is to evaluate the methodology, evidence and reporting quality of SRs/MAs of the effects of HIIT on patients with T2DM.

Methods

PubMed, Embase, Cochrane Library, Web of Science, CNKI, WanFang Data, SinoMed and VIP were searched. A MeaSurement Tool to Assess

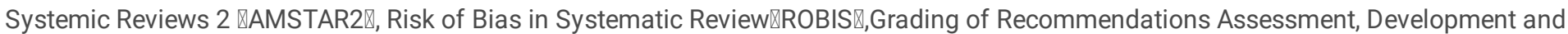
Evaluation囚GRADE囚were used to evaluate the included studies.

Results

Six SRs/MAs studies were included, with 79 outcomes from 21 original studies. Methodological quality of AMSTAR2 evaluation was extremely low. ROBIS evaluation showed high risk of bias. There are 39 outcomes of 3 included SRs/MAs used GRADE, of which 29 items are low, 8 items are very low, and 2 items are intermediate quality. Low quality and very low quality evidence bodies account for $95 \%$ of the total.

Conclusions

SRs/MAs on the effect of HIIT intervention on patients with T2DM included a small number of original studies and the overlapping feature is obvious, outcomes are diverse and overlapping, and there is a lack of key and ending outcomes; From original study, outcomes to system reviews, quality of evaluation is low. Evidence from a large samples, long periods, better protocols, and reflecting ending outcomes and critical outcomes are needed to promote the application of HIIT in T2DM.

\section{Background}

Human beings are facing the threat of absolute excess nutrition and continuous reduction of physical activity opportunities, leading to the spread of Type 2 Diabetic Mellitus(T2DM) worldwide[1]. T2DM can harm many organs of the body and seriously affect the quality of life. Increasing the level of physical activity will delay the process of T2DM deterioration, that is, exercise is an important strategy for adjuvant treatment and rehabilitation on patients with T2DM[2]. However, it is difficult for patients with T2DM to fully abide by and implement traditional exercise concepts. New exercise concepts and methods are needed. High-intensity Interval Training (HIIT) which has achieved good effects in the fields of athletics, may provide a time-efficient solution to improve health of patients with T2DM, and has been gradually applied in the field of medical treatment and rehabilitation in recent years. With the increasing number of original experimental studies on HIIT intervention in patients with T2DM, the understanding of the effect of HIIT on T2DM is different or even contradictory. Therefore, the number of Systematic Reviews/Meta-Analysis (SRs/MAs) studies on the effect of HIIT intervention in patients with T2DM is also increasing. SRs/MAs is the best way to present the results of current evidential synthesis studies in clinical decision-making. High quality SRs/MAs is one of the highest levels of evidence at present, which can provide decision-making basis for clinicians, patients with T2DM and other institutions and participants of T2DM prevention and treatment. But a single research often focuses on a particular point, different SRs/MAs have different qualities, and the differences in completion time and included studies may lead to different conclusions. There are some gaps from the laboratory to public health policy[3]. Based on these issues should be comprehensively assessed. An Overview of Systematic Reviews (OoSRs) is used in this paper to evaluate existing SRs/MAs. Through comprehensive collection of HIIT for the integration and analysis of SRs/MAs in the treatment and rehabilitation of T2DM, the quality of methodology, the quality of evidence and the quality of reporting on the effect of HIIT intervention on T2DM was comprehensively evaluated. Trying to clarify the context of the existing problems, to provide high-quality summary of evidence for HIIT intervention in T2DM, and to provide a reference for further research on HIIT intervention in T2DM.

Due to the PROSPERO does not currently accept registrations for OoSRs. PROSPERO is therefore unable to accept the application or provide a registration number. But the research proposal will be published in the Bulletin of Sports Science and Technology, No.2, February 2022 (Article No.: 20220144).

\section{Methods}




\section{Inclusion and exclusion criteria inclusion criteria}

$\triangle$ Participants: T2DM patients. The country, race, place of origin, educational level, age and gender of the participants were not limited.

(2) Interventions: HIIT, type, movement time, interval time, duration, frequency are all unlimited. Control group: unlimited.

(3) Outcomes: unlimited.

(4) Type of studies: SRs /MAs.

\section{Exclusion criteria}

\Repetitive research literature.

\Research methods are not SRs/MAs literature, Including experimental studies, epidemiological studies, case studies

\Participants were not or not only patients with T2DM, Patients with pre-T2DM will be excluded from the study.

هSystematic evaluation plan, traditional review (no clear retrieval strategy, inclusion and exclusion criteria, evaluation methods of literature quality), and literature that cannot be obtained in full text (conference abstract, etc.).

\section{Search Strategies}

Databases include PubMed, Embase, The Cochrane Library and Web of Science were searched by computer; Chinese databases were searched including CNKI, WanFang Data, SinoMed and VIP. Database were searched up to June 1, 2020. Flowchart is reported as PRISMA2009, but full search strategies for all databases are presented as PRISMA2020. The full-search strategy is available in Additional file 2.

Literature screening and extraction

Literature screening: the literature retrieved from the database is imported into the Endnote software. Duplicates were eliminated by means of Find Duplicates combined with researchers' manual comparison and verification; Two reviewers (Fei and Jun) independently read the titles and abstracts of the literature, and excluded the literature according to the exclusion criteria; The full text of the literature that might be included in the study were collected, and if the network search lacks information, contact the author by email to supplement it. The full-text articles were assessed and data extracted by Two reviewers (Fei and Jun) independently. Extracted data were put into the pre-designed tables.

\section{Methodological evaluation of included studies}

Methodological Quality Evaluation: A MeaSurement Tool to Assess Systemic Reviews 2 (AMSTAR 2)[4]区

Risk assessment of bias: Risk of Bias in Systematic Review(ROBIS)[5]凹

Quality evaluation of evidence: Grading of Recommendations Assessment, Development and Evaluation (GRADE)[6-10].

Methodological quality was assessed independently by Lan and Jun in groups, and any discrepancies have been resolved by discussion. Data extraction and quality assessment were undertaken on Microsoft Excel spreadsheets.

\section{Results}

\section{Literature retrieval and screening}

A total of 134 literatures were obtained by preliminary examination, including 13 articles in Chinese, 121 articles in English. Import Endnote software, by find duplicates, excluding 46 duplicates, Of these, 7 in Chinese and 39 in English. Reading topics and abstracts, according to the exclusion criteria, Excluding 76 articles. Twelve papers were included in the full text, of which 2 were in Chinese, 10 articles in English; One paper lacks full text, to contact the author via email for supplements. The paper was written in Spanish and read after translation through Youdao. Six articles[11-16] were finally included in the SRs/MAs, 1 article[14] in Chinese, 5 articles[11-13, 15, 16]in English; The process and results of literature screening is shown in Fig.1. 


\section{Basic characteristics of inclusion and exclusion studies}

The basic characteristics of the 6 included SRs/MAs studies are shown in Table 1. According to the year of publication, three papers in 2019[11-13], two in 2018[14, 15], and one in 2015[16]. According to the language, one in Chinese for MA study[14], five in English including two SRs/MAs[11, 13], one MA[15] and two SRs papers[12, 16]. According to type of original study included ,five randomized controlled trials (RCT)[11-15],one was included in the pre-/post-test(PPT) studies[16]; The number of original studies included ranged from five to 13; The sample size ranged from 84 to 345 ; The participants ranged in age from 15 to 70 . The intervention group was HIIT.

Table 1 Basic characteristics of studies included 


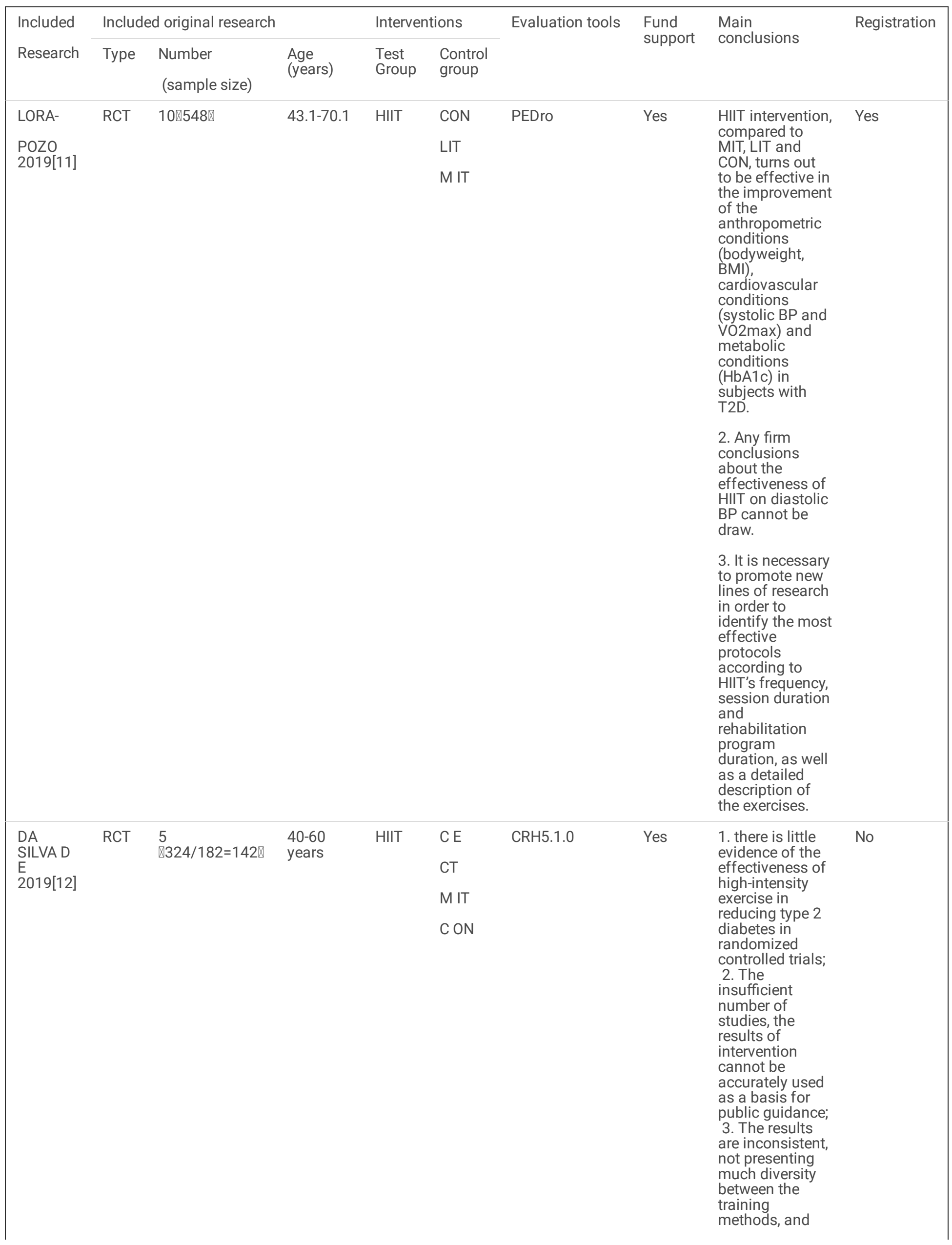




\begin{tabular}{|c|c|c|c|c|c|c|c|c|c|}
\hline & & & & & & & & $\begin{array}{l}\text { the different } \\
\text { methods of } \\
\text { volume and } \\
\text { intensity } \\
\text { control training. }\end{array}$ & \\
\hline $\begin{array}{l}\text { LIU J-X } \\
2019[13]\end{array}$ & RCT & $13 \llbracket 345 \rrbracket$ & $\begin{array}{l}15-70 \\
\text { years }\end{array}$ & HIIT & $\begin{array}{l}\text { CON } \\
\text { MICT }\end{array}$ & $\begin{array}{l}\text { CCT } \\
\text { GRADE }\end{array}$ & Yes & $\begin{array}{l}\text { 1. HIIT is an } \\
\text { effective } \\
\text { strategy for } \\
\text { improving } \\
\text { cardiorespiratory } \\
\text { fitness in } \\
\text { patients with } \\
\text { T2D, preferable } \\
\text { to MICT. } \\
\text { 2. Results } \\
\text { related to other } \\
\text { parameters } \\
\text { associated with } \\
\text { the prognosis of } \\
\text { T2D, such as } \\
\text { HbA1c, body } \\
\text { weight, and BMI, } \\
\text { were not } \\
\text { conclusive. } \\
3 . \text { Future } \\
\text { studies should } \\
\text { investigate the } \\
\text { effects of HIIT in } \\
\text { T2D patients } \\
\text { through } \\
\text { multicenter } \\
\text { RCTs with large } \\
\text { sample sizes } \\
\text { over the long } \\
\text { term. }\end{array}$ & No \\
\hline $\begin{array}{l}\text { CHEN B- } \\
\text { L } \\
2018[14]\end{array}$ & RCT & $8(275)$ & $\geqq 18$ & HIIT & $\begin{array}{l}\text { MICT } \\
\text { CON }\end{array}$ & $\begin{array}{l}\text { CRH5.1.0 } \\
\text { GRADE }\end{array}$ & Yes & $\begin{array}{l}\text { There is no } \\
\text { evidence } \\
\text { showed that } \\
\text { HIIT is more } \\
\text { effective on } \\
\text { blood glucose, } \\
\text { blood fat and } \\
\text { body } \\
\text { composition in } \\
\text { the patients with } \\
\text { T2DM, which } \\
\text { needs further } \\
\text { research. }\end{array}$ & Yes \\
\hline $\begin{array}{l}\text { DE } \\
\text { NARDI A } \\
\text { T } \\
2018[15]\end{array}$ & RCT & $5(120)$ & $61.7 \pm 6$ & HIIT & MICT & $\begin{array}{l}\text { CRH5.1.0 } \\
\text { GRADE }\end{array}$ & No & $\begin{array}{l}\text { High-intensity } \\
\text { interval training } \\
\text { has the potential } \\
\text { to be used as a } \\
\text { treatment } \\
\text { modality for } \\
\text { individuals with } \\
\text { prediabetes or } \\
\text { T2D. This } \\
\text { intervention } \\
\text { induces } \\
\text { cardiometabolic } \\
\text { adaptations } \\
\text { similar to those } \\
\text { of MICT and } \\
\text { provides greater } \\
\text { benefits to } \\
\text { functional } \\
\text { capacity in } \\
\text { patients with } \\
\text { T2D. However, } \\
\text { strong } \\
\text { supporting } \\
\text { research is } \\
\text { further needed. }\end{array}$ & Yes \\
\hline $\begin{array}{l}\text { CURRY } \\
M\end{array}$ & RCT & $6 \llbracket 84 \rrbracket$ & $\begin{array}{l}\text { Minimum } \\
\text { mean }\end{array}$ & HIIT & MICE & $25 \mathrm{P}$ & No & $\begin{array}{l}\text { 1.HIIT and MICE } \\
\text { do not }\end{array}$ & No \\
\hline
\end{tabular}


$\begin{array}{lll}\text { 2015[16] P PT } & \begin{array}{l}\text { age } 40.2 \\ \text { years }\end{array}\end{array}$

PPT

consistently

show significant

differences.

2. More

comprehensive

evidence is

available

concerning the

benefits of HIIT

in patients with

type 2 diabetes

are needed.

3 . it is

suggested that

future trials

increase the

duration of data

collection (12-

24 months) in

order to yield

more conclusive

evidence.

4. The

professionals

who study the

effects of

exercise and

type2 diabetes

should build a

consensus on

standardized

outcomes.

The control group included Continuous Exercise (CE), Continuous Training (CT), Moderate Intensity Training (MIT) and Moderate-Intensity Continuous Training (MICT), moderate-intensity continuous exercise (MICE), moderate Intensity interval Training (MMIIT) and Low Intensity Training (LIT), No Exercise or quiet and routine treatment (CON), etc. In terms of quality assessment, Cochrane evaluation tools are mainly used for bias risk assessment, and three of them adopted Cochrane Reviewers' Handbook Version 5.1 (CRH5.1)[12, 14, 15], One by Cochrane Collaboration's tool (CCT)[13]; The other two use Pedro scale (Pedro) [11]and 25-point Standardized Checklist(25P)[16]. The quality of evidence in three literatures was evaluated by GRADE[13-15]; Four noted fund support, of which three were funded[11, 13, 14], one stated that it was not funded[15], and all of the studies did not provide funding for inclusion in original study.

Six excluded studies and the reasons for exclusion are shown in Table 2 . The reasons for exclusion are mainly as follows: participants of the study include other groups of people, such as healthy people, overweight people, sedentary people; there is no clear retrieval strategy, inclusion and exclusion criteria, and evaluation methods of literature quality.

Table 2 Excluded articles and reason for exclusion

\begin{tabular}{|c|c|}
\hline Research & Exclusion grounds \\
\hline $\begin{array}{l}\text { DE OCA } \\
\text { 2019[17] }\end{array}$ & $\begin{array}{l}\text { narrative review, Participants of the study include other groups of people, such as healthy people, overweight people, } \\
\text { sedentary people; The literature quality evaluation methods such as methodological research results were not used. }\end{array}$ \\
\hline $\begin{array}{l}\text { WORMGOOR } \\
\text { S G 2017[18] }\end{array}$ & narrative review, literature quality evaluation methods such as methodological research results were not used. \\
\hline $\begin{array}{l}\text { FRANCOIS M } \\
\text { E 2015[19] }\end{array}$ & There is no clear retrieval strategy, inclusion and exclusion criteria, evaluation method of literature quality. \\
\hline $\begin{array}{l}\text { LITTLE J P } \\
\text { 2014[20] }\end{array}$ & There is no clear retrieval strategy, inclusion and exclusion criteria, evaluation method of literature quality. \\
\hline $\begin{array}{l}\text { JELLEYMAN } \\
\text { C 2015[21] }\end{array}$ & $\begin{array}{l}\text { The participants of the study include other groups of people, such as healthy people, overweight people, sedentary } \\
\text { people. }\end{array}$ \\
\hline $\begin{array}{l}\text { Cheng-ji } \\
\text { Han 2019[22] }\end{array}$ & There is no retrieval strategy, inclusion and exclusion criteria, evaluation method of literature quality. \\
\hline
\end{tabular}

As shown in Fig.2, A total of 21 original studies were included in six SRs/MAs. If the original study was published after or in the same year as the SRs/MAs, the total will not be included. Three original studies were included in all included SRs/MAs, as follows: MAILLARD F2016[23], MITRANUN W2014[24] and TERADA T2013[25]. HOLLEKIM-STRAND S M2014[26], KARSTOFT K2013[27], STOA EM2017[28], ALVAREZ C2016[29] and CASSIDY S2016[30] were included in three or more SRs/MAs. There are 13 original studies were included by only 
one SRs/MAs and it's on the edge of the figure, as follows: TERADA T2013[25], SHABAN N2014[31], GILLEN J B2012[32], LITTLE J P2011[33] were included in CURRY M,2015[16]. Two papers of TERADA T 2013[25, 34] are the same research. others are Pre and post control studies. ROBINSON E2015[35], KARSTOFT K2014[36] were included in CHEN B-L 2018. The participants included in ROBINSON E2015[35] are sedentary adults. KARSTOFT K2014[36] is the same study as KARSTOFT K 2013[27].WINDING KM2018[37], BELLIA A2017[38], RAMOS JS2016[39], LEE SS2015[40], BACKX K2011[41] were included in LIU J-X 2019[13]. Participants included in RAMOS JS2016[39], LEE SS2015[40] are persons with metabolic syndrome, Adolescent patients with T2DM. RUFFINO J S2017[42], BALDUCCI S2012[43] were included in LORA-POZO,2019[11]. In fact, the intervention of BALDUCCI S2012 is the moderate-to-high intensity exercise that performed aerobic training at 70\% of predicted V02max and resistance training at 60\% of predicted 1-RM(Repetition Maximum)[43].

\section{Evaluation results of AMSTAR2}

The evaluation results of AMSTAR2 tools are shown in Table 3. The evaluation results of key items are "yes" as follows: item 2 is $33.3 \%$ (2/6), item 4 is $66.7 \%(4 / 6)$, item 7 is $16.7 \%(1 / 6)$, item 9 is $83.3 \%(5 / 6)$, item 11 is $66.7 \%(4 / 6)$, item 13 is $16.7 \%(1 / 6)$, item 15 is $0(0 / 6)$. For other items, the evaluation result of "yes" is $100 \%$ for items 1,5 and 8 , item 6 is $83.3 \%(5 / 6)$, item 14 is $66.7 \%(4 / 6)$, item 16 is $50 \%(3 / 6)$, item 12 is $33.3 \%(2 / 6)$, item 3 and 10 are $0(0 / 6)$. Using the AMSTAR2 tools, the final quality evaluation is extremely low.

Table3 Evaluation results of AMSTAR2 tools

\begin{tabular}{|llllllllllllllllll|}
\hline Author (year) & 1 & 2 & 3 & 4 & 5 & 6 & 7 & 8 & 9 & 10 & 11 & 12 & 13 & 14 & 15 & 16 & Quality rating \\
\hline LORA-POZO 2019 & Y & Y & N & N & Y & Y & N & Y & Y & N & Y & Y & N & Y & N & Y & Very low \\
DA SILVA & Y & N & N & Y & Y & Y & N & Y & Y & N & N & N & N & N & N & N & Very low \\
DE 2019 & & & & & & & & & & & & & & & & & \\
LIU J-X 2019 & Y & N & N & Y & Y & Y & N & Y & Y & N & Y & N & N & N & N & Y & Very low \\
CHEN B-L 2018 & Y & PY & N & Y & Y & Y & N & Y & Y & N & Y & N & N & Y & N & N & Very low \\
DE NARDI & Y & Y & N & Y & Y & Y & N & Y & Y & N & Y & Y & Y & Y & N & Y & Very low \\
AT 2018 & & & & & & & & & & & & & & & & & \\
CURRY M & Y & N & N & N & Y & N & Y & Y & Y & N & N & N & N & Y & N & N & Very low \\
2015 & & & & & & & & & & & & & & & & & \\
\hline
\end{tabular}

Note: $\mathrm{Y}$ is Yes, $\mathrm{PY}$ is Partial Yes, $\mathrm{N}$ is No.

\section{Risk of bias rating}

Because this study is OoSRs, only to assess the risk of bias of SRs/MAs, the first phase can be skipped. The second phase focuses on identifying possible biases during the each process of production OoSRs, include 4 domains. The third phase is to judge the overall bias risk of SRs/MAs, as shown in Table 4, the results of phase three are all for high risk.

Table 4 Evaluation results of ROBIS tools included in the study (phases II and III) 


\begin{tabular}{|llllll|}
\hline Author (year) & Phase II & & & & Phase III \\
\cline { 2 - 5 } & DOMAIN1 & DOMAIN2 & DOMAIN3 & DOMAIN4 & Judging Risk of bias \\
LORA-POZO & Low & High & Low & High & High \\
2019 & & & & & \\
\hline DA SILVA D E 2019 & Uncertainty & High & Low & High & High \\
\hline LIU J-X2019 & Uncertainty & Low & Low & High & High \\
CHEN B-L & Uncertainty & High & Low & High & High \\
2018 & & & & & \\
\hline $\begin{array}{l}\text { DE NAR D AT } \\
\text { 2018 }\end{array}$ & Low & Low & Low & High & High \\
CURRY M 2015 & Uncertainty & High & Low & High & High \\
\hline
\end{tabular}

\section{The evaluation results of the quality of evidence}

According to the outcomes list of all included SRs/MAs studies (number of original studies included), there are 79 outcomes (included in 21 original studies). As shown in Fig.3, Lora-Pozo2019 has 8 (10) items[11], DA SILVA DE 2019 has 13(5) items[12], LIU J-X2019 has 13(13) items[13], CHEN B-L 2018 has 56(8) items[14], DE NARDI AT2018 has 14(5) items[15], CURRY M2015 has 29(6) items[16], The bubble size in the figure reflects the ratio of the number of included outcomes to the number of included original studies.

As shown in Fig.4, Outcomes of Liu J-X2019[13]HIIT VS CON included 11 items, HIIT VS MICT included 13 items; Outcomes of CHEN B-L 2018[14] included 12 items; Outcomes of DE NARDI AT2018[15] included 12 items. The red color in the figure indicates that the statistical difference was significant between the two groups, and the bubble size indicates the absolute value of the effect amount. Based on the principles of careful evaluation and citation, Results of GRADE systematic review based on the above three SRs/MAs studies were 39 items. Among them, 29 items were low quality, eight items were very low quality and two items of intermediate quality. Low quality and very low quality evidence bodies account for $95 \%$ of the total.

\section{Discussion}

What are the real effect of HIIT intervention on body and mental health in patients with T2DM? How about security? what about HIIT compliance and long-term adherence among T2DM patients? The above problems, as if all included SRs/MAs are ignored. Although there's a lot of evidence support the use of HIIT in healthy individuals and those with physical health disorders spanning an entire age range. It should be noted that, from the included original studies, participants were complex but the number of studies was small, and HIIT is not classified according to training protocol but the control group showed diversity. All T2DM patients included in the SRs/MAs study were not differentiated by course of disease, gender, ethnicity, etc. T2DM is a complex metabolic disease, and the patient differences showed great differences in T2DM transformation. For example, there were great differences in physical function, cognition, economic basis and other aspects between the adolescents and the elderly T2DM patients. Therefore, participants of a research are the premise factor to improve the reliability, and are also the one of main reason for the final exclusion of the six articles. HIIT due to different changes in the diversity of exercise types (walking, running or jogging, cycling), exercise load (duration, intensity, frequency), and interval schemes (intermittent mode, time, intensity, frequency) and time span of exercise interventions. Comparison groups include CE, CT, MIT, MICT, MICE, MMIIT, LIT, as well as CON for quiet or conventional treatment, which also showed the diversity and complexity.

Evidence body of 79 outcomes from 21 original studies listed in all currently included SRs/MAs. As shown in Fig. 2, the original studies included in different SRs/MAs have overlapped each other. Nearly $50 \%$ of the original studies overlap directly or indirectly. The same research was repeatedly cited, or even inappropriate research was included in SRs/MAs. Based on the above analysis, it is more meaningful to take "there is no retrieval strategy, inclusion and exclusion criteria, evaluation method of literature quality" as the main reason in literature exclusion to improve the accuracy and reliability of the research. All body of evidence included SRs/MAs can be divided into blood biochemical outcomes, anthropometric outcomes, physiological outcomes, physical activity performance and physical fitness, and so on. It was characterized by large amount of evidence, diversity and complexity of outcomes. There is data overlap among the outcomes of the original study. Compared with CON or MICT, the effect of HIIT does not show a wide range of advantages.

AMSTAR2 results showed that methodology quality evaluations of all included 6 SRs/MAs were "extremely low". In SRs/MAs, researchers should ensure that each step of the methodology is scientific, rigorous and comprehensive, in order to better provide an accurate basis for 
practice. The AMSTAR2 rating is an overall quality assessment in the form of a "confidence" rating based on key items, focusing on weaknesses in key areas and avoiding key weaknesses that may be masked by high scores. Such as inadequate literature search or inclusion of individual studies that failed to assess the risk of bias[44]. AMSTAR2 sets a very high threshold that makes overall rating requirements high. The vast majority of SRs/MAs studies were rated "very low", which appears to produce a floor effect, but the quality of the methodology in the Cochrane and NICE guidelines is better than other SRs, suggesting that this high standard is justified[45], It is suggested that the methodological quality of SRs/MAs studies in this field should be improved.

The ROBIS tool is more focused than AMSTAR2 on assessing the risk of bias in SRs/MAs studies. The final evaluation results of the six included SRs/MAs studies are all high risk. The included SRs/MAs studies were evaluated by the ROBIS tool, which is different from the risk bias assessment of the original studies. It may be that the risk of bias in the original study is high but the risk of bias in the SRs/MAs study is low [46]. The former is a flaw in the study itself and the latter is methodological bias. Last, all included studies did not analyze the risk of bias in depth and detail, and proposed solutions. The number of evidences included in the study is large, but there is selective analysis, which increases the risk of bias. The above is the direct cause of high risk. AMSTAR and ROBIS tools can be viewed as complementary tools when assessing the quality of the SRs[47]区

Whether the outcomes of HIIT effect on T2DM patients or the conclusion of the study can truly and correctly reflect the actual situation, and whether the outcomes of T2DM can be objectively and accurately reflected, both need to review and evaluate the evidence body of the study. GRADE provides clear and comprehensive criteria for reducing or improving the quality of evidence ratings, and is a structured, processtransparent approach[48]. Three of the 6 included SRs /MAs [13-15] used GRADE to evaluate evidence quality. With a cautious attitude, evidence body directly quoting GRADE evaluation results showed that more than $95 \%$ were low or very low. The main cause of low quality evidence is inaccuracy and inconsistency of evidence. All evidence bodies showed imprecision. Limitations were also the main cause of the decline in the quality of evidence. There may be differences in researchers' grasp of the scale. The evaluation of AMSTAR2, ROBIS and GRADE is closely related. Quality of evidence is the basis of judging methodological quality and bias risk, which can be evaluated from the original research level, body of evidence level and systematic evaluation level.

\section{Strengths}

systematically and comprehensively searched the MAs/SRs literature on HIIT intervention of patients with T2DM, Therefore, more outcomes were evaluated. All the participants included in this study were T2DM patients with definite diagnosis, which eliminated the interference caused by non-T2DM population to a large extent, making the study results more reliable.

\section{Limitations}

The included intervention and comparison group of SRs/MAs were relatively complex, with a large number of outcomes, but the number of original studies were limited and there was some heterogeneity, and no quantitative combined analysis of effect value was conducted. The quality of the included SRs/MAs studies was not high, the overlap of the original studies was prominent, and the quality of evidence was not high, which may affect the accuracy of the OoSRs. No statistical analysis was performed for all outcomes.

\section{Conclusions}

SRs/MAs on the effect of HIIT intervention on patients with T2DM included a small number of original studies and the overlapping feature is obvious, outcomes are diverse and overlapping, and there is a lack of key and ending outcomes; From original study, outcomes to system reviews, quality of evaluation is low. Evidence from a large samples, long periods, better protocols, and reflecting ending outcomes and critical outcomes are needed to promote the application of HIIT in T2DM..

\section{Abbreviations}

\section{T2DM}

Type 2 Diabetes Mellitus; HIIT:High Intensity Interval Training; SRs/MAs:Systematic Reviews/Meta-Analysis; OoSRs:Overview of Systematic Reviews; PRISMA:Preferred Reporting Items for Systematic Reviews and Meta Analyses; AMSTAR2:A MeaSurement Tool to Assess Systemic Reviews 2; ROBIS:Risk of Bias in Systematic Review; GRADE:Grading of Recommendations Assessment, Development and Evaluation; RCT:randomized controlled trials; PPT:pre-/post-test; CE:Continuous Exercise; CT:Continuous Training; MIT:Moderate Intensity Training; MICT:Moderate-Intensity Continuous Training; MICE:moderate-intensity continuous exercise; MMIIT:moderate Intensity interval Training; LIT:Low Intensity Training; CON:No Exercise or quiet and routine treatment; CRH5.1:Cochrane Reviewers' Handbook Version 5.1; CCT:Cochrane Collaboration's tool; Pedro:Pedro scale; 25P:25-point Standardized Checklist; 1-RM:1 repetition maximum 


\section{Declarations}

\section{Ethics approval and consent to participate}

The paper is an Overview of Systematic Reviews and Meta-Analyses, and only employs published research data. There were no human participants, and this study does not require approval of our University ethics committee.

\section{Consent for publication}

Not applicable.

\section{Availability of data and materials}

Data will be available on request from the corresponding author.

\section{Competing interests}

The authors report no potential conflicts of interest.

\section{Funding}

Open Research Fund of Key Laboratory of Physical Fitness and Exercise Rehabilitation of Hunan Province (Project No.: 19pfer006)

\section{Acknowledgements}

We would like to thank Yu-Jia Cai and Yong-Gang Zhang, Editor, of Chinese Journal of Evidence-Based Medicine Press, for their valuable suggestions during the entire project. Thank Professor de Oca Gancia, Adrian Montes for providing his paper by email.

\section{Author Contributions}

Jun Tan, Lan Zheng and Jin-Hui Tian collectively contributed to the conception of this overview. Jun Tan, Lan Zheng, Fei Yu and Xing Wang were involved in the literature search, screening, and extraction steps. Analysis and manuscript drafting were implemented by Jun Tan with support from all other authors. and all authors contributed to the final version.

\section{Author details}

1.Key Laboratory of Physical Fitness and Exercise Rehabilitation of Hunan Province,

National Demonstration Center for Experimental Physical Education,College of Physical Education, Hunan Normal University, Changsha, 410012, China. 2.Evidence-based Medicine Center, Evidence-based Nursing Center, Lanzhou University, Lanzhou, 730000, China. 3. The First People's Hospital of Hefei, Hefei, 230001, China. 4.The First Clinical Medical College of Lanzhou University, Lanzhou,730000, China.

Jun Tan, juntan@hunnu.edu.cn; Jin-Hui Tian, tianjh@lzu.edu.cn;

Fei Yu, 1622260247@qq.com; Xing Wang, wx1910292529@163.com

\section{References}

1. International Diabetes Federation Diabetes Atlas. 9th edition https://diabetesatlas.org/upload/resources/2019/IDF_Atlas_9th_Edition_2019.pdf.

2. WHO\&IDF. HEARTS D: diagnosis and management of type 2 diabetes; 2020.04.22:14-16.

3. Gray SR, Ferguson C, Birch K, Forrest LJ, Gill JMR. High-intensity interval training: key data needed to bridge the gap from laboratory to public health policy. Br J Sports Med. 2016;50(20):1231-U1219.

4. Shea BJ, Reeves BC, Wells G, Thuku M, Hamel C, Moran J, Moher D, Tugwell P, Welch V, Kristjansson E, et al. AMSTAR 2: a critical appraisal tool for systematic reviews that include randomised or non-randomised studies of healthcare interventions, or both. BMJ. 2017;358:1-9.

5. Whiting P, Savovic J, Higgins JPT, Caldwell DM, Reeves BC, Shea B, Davies P, Kleijnen J, Churchill R, Grp R. ROBIS: A new tool to assess risk of bias in systematic reviews was developed. J Clin Epidemiol. 2016;69:225-34. 
6. Guyatt GH, Oxman AD, Kunz R, Brozek J, Alonso-Coello P, Rind D, Devereaux PJ, Montori VM, Freyschuss B, Vist G, et al. GRADE guidelines 6. Rating the quality of evidence-imprecision. J Clin Epidemiol. 2011;64(12):1283-93.

7. Guyatt GH, Oxman AD, Vist G, Kunz R, Brozek J, Alonso-Coello P, Montori V, Akl EA, Djulbegovic B, Falck-Ytter Y, et al. GRADE guidelines: 4. Rating the quality of evidence-study limitations (risk of bias). J Clin Epidemiol. 2011;64(4):407-15.

8. Nolting A, Perleth M, Langer G, Meerpohl JJ, Gartlehner G, Kaminski-Hartenthaler A, Schünemann HJ. [GRADE guidelines: 5. Rating the quality of evidence: publication bias]. Z Evid Fortbild Qual Gesundhwes. 2012;106(9):670-6.

9. Guyatt GH, Oxman AD, Kunz R, Woodcock J, Brozek J, Helfand M, Alonso-Coello P, Glasziou P, Jaeschke R, Akl EA, et al. GRADE guidelines: 7. Rating the quality of evidence-inconsistency. J Clin Epidemiol. 2011;64(12):1294-302.

10. Guyatt GH, Oxman AD, Kunz R, Woodcock J, Brozek J, Helfand M, Alonso-Coello P, Falck-Ytter Y, Jaeschke R, Vist G, et al. GRADE guidelines: 8. Rating the quality of evidence-indirectness. J Clin Epidemiol. 2011;64(12):1303-10.

11. Lora-Pozo I, Lucena-Anton D, Salazar A, Galan-Mercant A, Moral-Munoz JA. Anthropometric, Cardiopulmonary and Metabolic Benefits of the High-Intensity Interval Training Versus Moderate, Low-Intensity or Control for Type 2 Diabetes: Systematic Review and MetaAnalysis. Int J Environ Res Public Health 2019, 16(22).

12. da Silva DE, Grande AJ, Roever L, Tse G, Liu T, Biondi-Zoccai G, de Farias JM. High-Intensity Interval Training in Patients with Type 2 Diabetes Mellitus: a Systematic Review. Current Atherosclerosis Reports. 2019;21(2):8.

13. Liu J-x, Zhu L, Li P-j, Li N, Xu Y-b. Effectiveness of high-intensity interval training on glycemic control and cardiorespiratory fitness in patients with type 2 diabetes: a systematic review and meta-analysis. Aging Clin Exp Res. 2019;31(5):575-93.

14. Chen BL, Guo JB. Effects of high intensity interval training on type 2 diabetes mellitus: a meta-analysis [J]. Chin J Rehabil Theory Pract. 2018;24(3):353-62.

15. De Nardi AT, Tolves T, Lenzi TL, Signori LU, Silva A. High-intensity interval training versus continuous training on physiological and metabolic variables in prediabetes and type 2 diabetes: A meta-analysis. Diabetes Res Clin Pract. 2018;137:149-59.

16. Curry M, Mehta SP, Chaffin JC, Duran E, Washington B, Bose SS. The effect of low-volume, high-intensity interval training on blood glucose markers, anthropometric measurements, and cardiorespiratory fitness in patients with type 2 diabetes. Critical Reviews in Physical Rehabilitation Medicine. 2015;27(1):19-35.

17. de Oca Gancia AM, Gutierrez-Manzanedo JV, Ponce Gonzalez JG. High-Intensity Interval Training (HIIT) as a therapeutic tool in patients with Type 2 Diabetes Mellitus: A narrative review. Retos-Nuevas Tendencias En Educacion Fisica Deporte Y Recreacion 2019(36):633639.

18. Wormgoor SG, Dalleck LC, Zinn C, Harris NK. Effects of High-Intensity Interval Training on People Living with Type 2 Diabetes: A Narrative Review. Canadian Journal of Diabetes. 2017;41(5):536-47.

19. Francois ME, Little JP. Effectiveness and safety of high-intensity interval training in patients with type 2 diabetes. Diabetes Spectr. 2015;28(1):39-44.

20. Little JP, Francois ME. High-intensity interval training for improving postprandial hyperglycemia. Res Q Exerc Sport. 2014;85(4):451-6.

21. Jelleyman C, Yates T, O'Donovan G, Gray LJ, King JA, Khunti K, Davies MJ. The effects of high-intensity interval training on glucose regulation and insulin resistance: A meta-analysis. Obes Rev. 2015;16(11):942-61.

22. Han-cheng J. Effect of high intensity interval training on type 2 diabetes mellitus. Contemporary Sports Technology. 2019;9(11):10,12.

23. Maillard F, Rousset S, Pereira B, Traore A, Del Amaze PdP, Boirie Y, Duclos M, Boisseau N. High-intensity interval training reduces abdominal fat mass in postmenopausal women with type 2 diabetes. Diabetes Metab. 2016;42(6):433-41.

24. Mitranun W, Deerochanawong C, Tanaka H, Suksom D. Continuous vs interval training on glycemic control and macroand microvascular reactivity in type 2 diabetic patients. Scand J Med Sci Sports. 2014;24(2):E69-76.

25. Terada T, Friesen A, Chahal BS, Bell GJ, McCargar LJ, Boule NG. Feasibility and preliminary efficacy of high intensity interval training in type 2 diabetes. Diabetes Res Clin Pract. 2013;99(2):120-9.

26. Hollekim-Strand SM, Bjorgaas MR, Albrektsen G, Tjonna AE, Wisloff U, Ingul CB. High-Intensity Interval Exercise Effectively Improves Cardiac Function in Patients With Type 2 Diabetes Mellitus and Diastolic Dysfunction A Randomized Controlled Trial. J Am Coll Cardiol. 2014;64(16):1758-60.

27. Karstoft K, Winding K, Knudsen SH, Nielsen JS, Thomsen C, Pedersen BK, Solomon TPJ. The Effects of Free-Living Interval Walking Training on Glycemic Control, Body Composition, and Physical Fitness in Type 2 Diabetic Patients A randomized, controlled trial. Diabetes Care. 2013;36(2):228-36.

28. Stoa EM, Meling S, Nyhus L-K, Stromstad G, Mangerud KM, Helgerud J, Bratland-Sanda S, Storen O. High-intensity aerobic interval training improves aerobic fitness and HbA1c among persons diagnosed with type 2 diabetes. Eur J Appl Physiol. 2017;117(3):455-67.

Page 12/17 
29. Alvarez C, Ramirez-Campillo R, Martinez-Salazar C, Mancilla R, Flores-Opazo M, Cano-Montoya J, Ciolac EG. Low-Volume High-Intensity Interval Training as a Therapy for Type 2 Diabetes. Int J Sports Med. 2016;37(9):723-9.

30. Cassidy S, Thoma C, Hallsworth K, Parikh J, Hollingsworth KG, Taylor R, Jakovljevic DG, Trenell MI. High intensity intermittent exercise improves cardiac structure and function and reduces liver fat in patients with type 2 diabetes: a randomised controlled trial.

Diabetologia. 2016;59(1):56-66.

31. Shaban N, Kenno KA, Milne KJ. The effects of a 2 week modified high intensity interval training program on the homeostatic model of insulin resistance (HOMA-IR) in adults with type 2 diabetes. J Sports Med Phys Fitness. 2014;54(2):203-9.

32. Gillen JB, Little JP, Punthakee Z, Tarnopolsky MA, Riddell MC, Gibala MJ. Acute high-intensity interval exercise reduces the postprandial glucose response and prevalence of hyperglycaemia in patients with type 2 diabetes. Diabetes Obesity Metabolism. 2012;14(6):575-7.

33. Little JP, Gillen JB, Percival ME, Safdar A, Tarnopolsky MA, Punthakee Z, Jung ME, Gibala MJ. Low-volume high-intensity interval training reduces hyperglycemia and increases muscle mitochondrial capacity in patients with type 2 diabetes. J Appl Physiol. 2011;111(6):1554-60.

34. Terada T, Friesen A, Chahal BS, Bell GJ, McCargar LJ, Boule NG. Exploring the Variability in Acute Glycemic Responses to Exercise in Type 2 Diabetes. Journal of Diabetes Research 2013:1-7.

35. Robinson E, Durrer C, Simtchouk S, Jung ME, Bourne JE, Voth E, Little JP. Short-term high-intensity interval and moderate-intensity continuous training reduce leukocyte TLR4 in inactive adults at elevated risk of type 2 diabetes. J Appl Physiol. 2015;119(5):508-16.

36. Karstoft K, Winding K, Knudsen SH, James NG, Scheel MM, Olesen J, Holst JJ, Pedersen BK, Solomon TPJ. Mechanisms behind the superior effects of interval vs continuous training on glycaemic control in individuals with type 2 diabetes: a randomised controlled trial. Diabetologia. 2014;57(10):2081-93.

37. Winding KM, Munch GW, lepsen UW, Van Hall G, Pedersen BK, Mortensen SP. The effect on glycaemic control of low-volume highintensity interval training versus endurance training in individuals with type 2 diabetes. Diabetes Obesity Metabolism. 2018;20(5):11319.

38. Bellia A, lellamo F, De Carli E, Andreadi A, Padua E, Lombardo M, Annino G, Campoli F, Tartaglione S, D'Ottavio S, et al. Exercise individualized by TRIMPi method reduces arterial stiffness in early onset type 2 diabetic patients: A randomized controlled trial with aerobic interval training. Int J Cardiol. 2017;248:314-9.

39. Ramos JS, Dalleck LC, Borrani F, Mallard AR, Clark B, Keating SE, Fassett RG, Coombes JS. The effect of different volumes of highintensity interval training on proinsulin in participants with the metabolic syndrome: a randomised trial. Diabetologia. 2016;59(11):2308-20.

40. Lee SS, Yoo JH, So YS. Effect of the low-versus high-intensity exercise training on endoplasmic reticulum stress and GLP-1 in adolescents with type 2 diabetes mellitus. Journal of Physical Therapy Science. 2015;27(10):3063-8.

41. Backx K, McCann A, Wasley D, Dunseath G, Luzio S, Owens D. The effect of a supported exercise programme in patients with newly diagnosed Type 2 diabetes: A pilot study. J Sports Sci. 2011;29(6):579-86.

42. Ruffino JS, Songsorn P, Haggett M, Edmonds D, Robinson AM, Thompson D, Vollaard NBJ. A comparison of the health benefits of reduced-exertion high-intensity interval training (REHIT) and moderate-intensity walking in type 2 diabetes patients. Applied Physiology Nutrition Metabolism. 2017;42(2):202-8.

43. Balducci S, Zanuso S, Cardelli P, Salvi L, Bazuro A, Pugliese L, Maccora C, lacobini C, Conti FG, Nicolucci A, et al. Effect of high- versus low-intensity supervised aerobic and resistance training on modifiable cardiovascular risk factors in type 2 diabetes; the Italian Diabetes and Exercise Study (IDES). PLoS One. 2012;7(11):e49297.

44. Ping N. Shi Jingpu. Update and Prospect of System Review and Meta-Analysis Revaluation. Chin J Evid Based Cardiovasc Med. 2018;10(10):1170-4.

45. C LR, Katja M, Dawid P, Uta W, Johannes M, Marc N, Olesja R, Jacqueline S, Simone F, Anja J. AMSTAR 2 overall confidence rating: lacking discriminating capacity or requirement of high methodological quality? Pubmed 2020, 119.

46. Qiong-fang WU, Hong-fan DING, Wei DENG, et al. ROBIS: A New Tool to Assess Risk of Bias in Systematic Reviews. Chin J Evid-based Med. 2015;15(12):1454-7.

47. Gomez-Garcia F, Ruano J, Gay-Mimbrera J, Aguilar-Luque M, Sanz-Cabanillas JL, Alcalde-Mellado P, Maestre-Lopez B, CarmonaFernandez PJ, Gonzalez-Padilla M, Garcia-Nieto AV, et al. Most systematic reviews of high methodological quality on psoriasis interventions are classified as high risk of bias using ROBIS tool. J Clin Epidemiol. 2017;92:79-88.

48. Guyatt GH, Oxman AD, Vist GE, Kunz R, Falck-Ytter Y, Alonso-Coello P, Schunemann HJ. Grp GW: GRADE: an emerging consensus on rating quality of evidence and strength of recommendations. Br Med J. 2008;336(7650):924-6. 


\section{Figures}

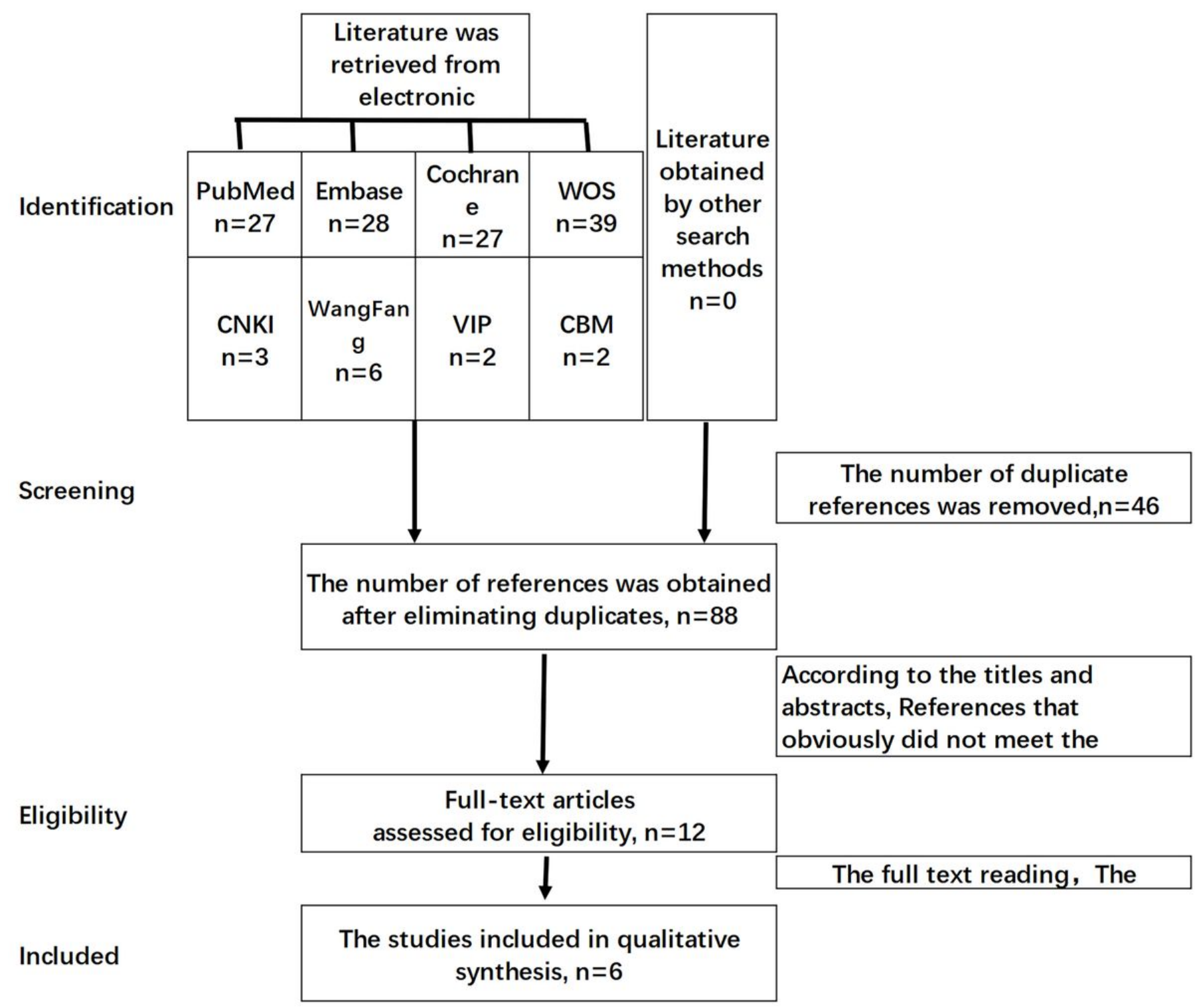

Figure 1

PRISMA 2009 flow diagram of the SRs/MAs literature search 


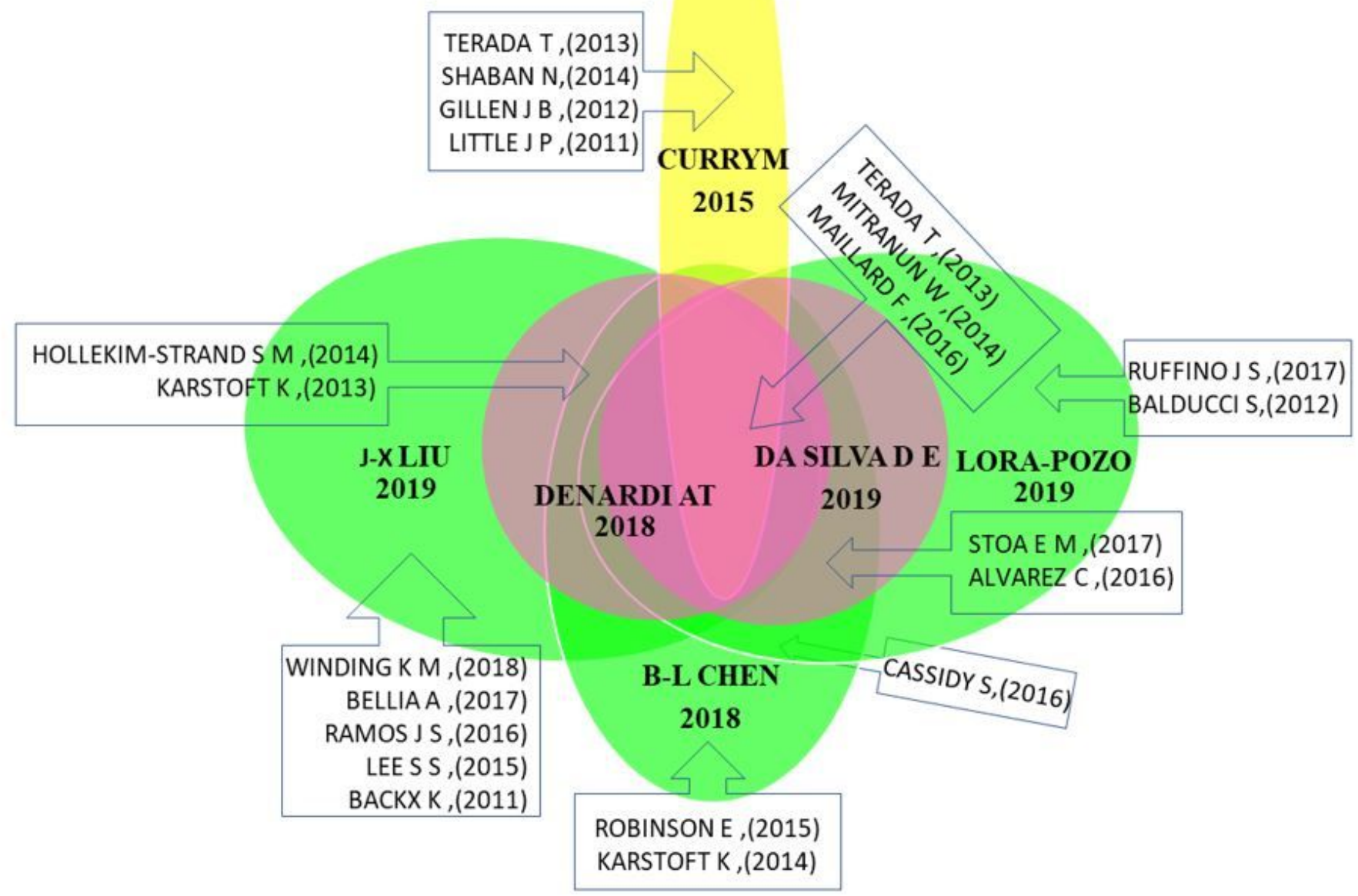

Figure 2

Original studies included in SRs /MAs and their distribution characteristics 


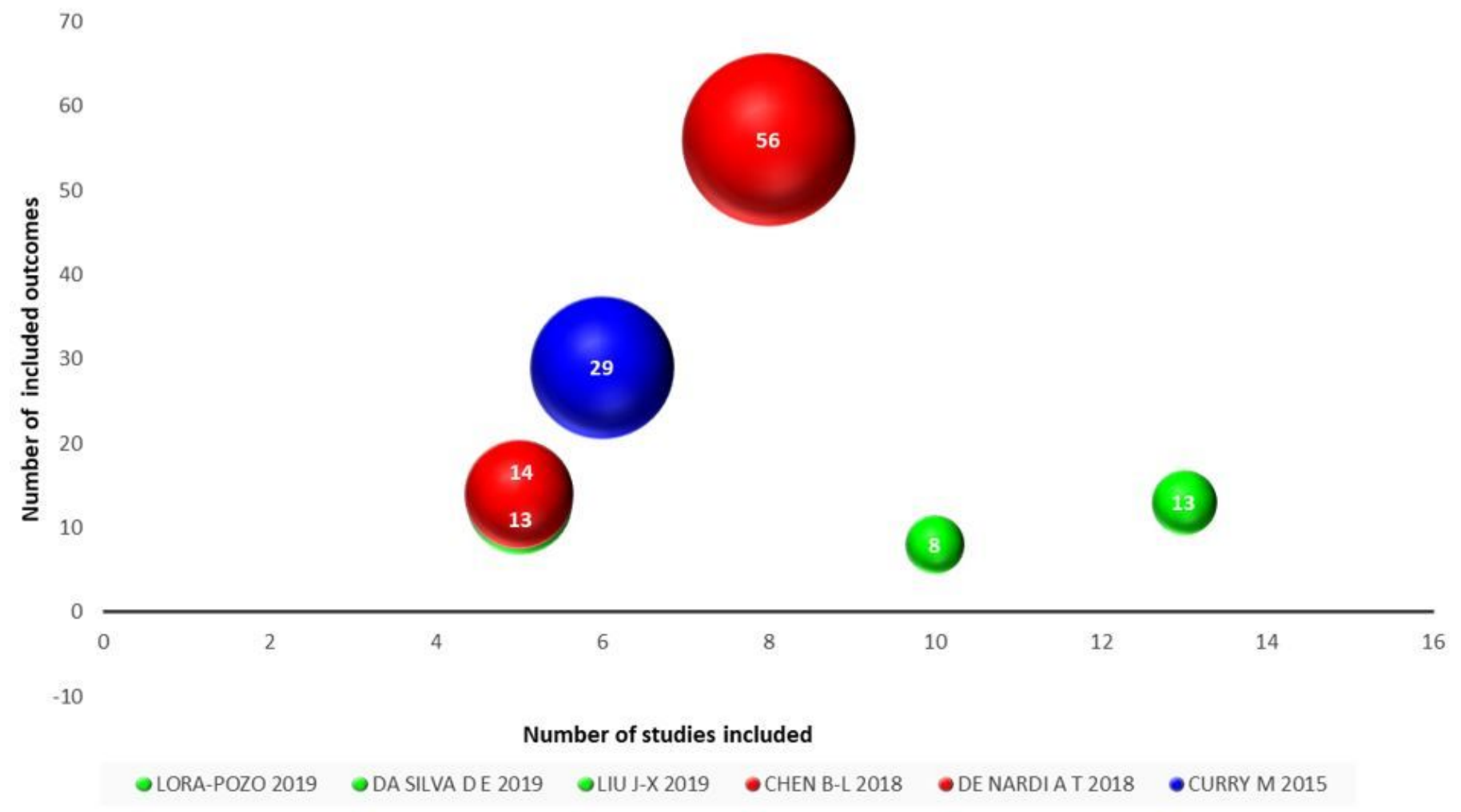

\section{Figure 3}

Number of outcomes listed in SRs/MAs studies (number of original studies included) 


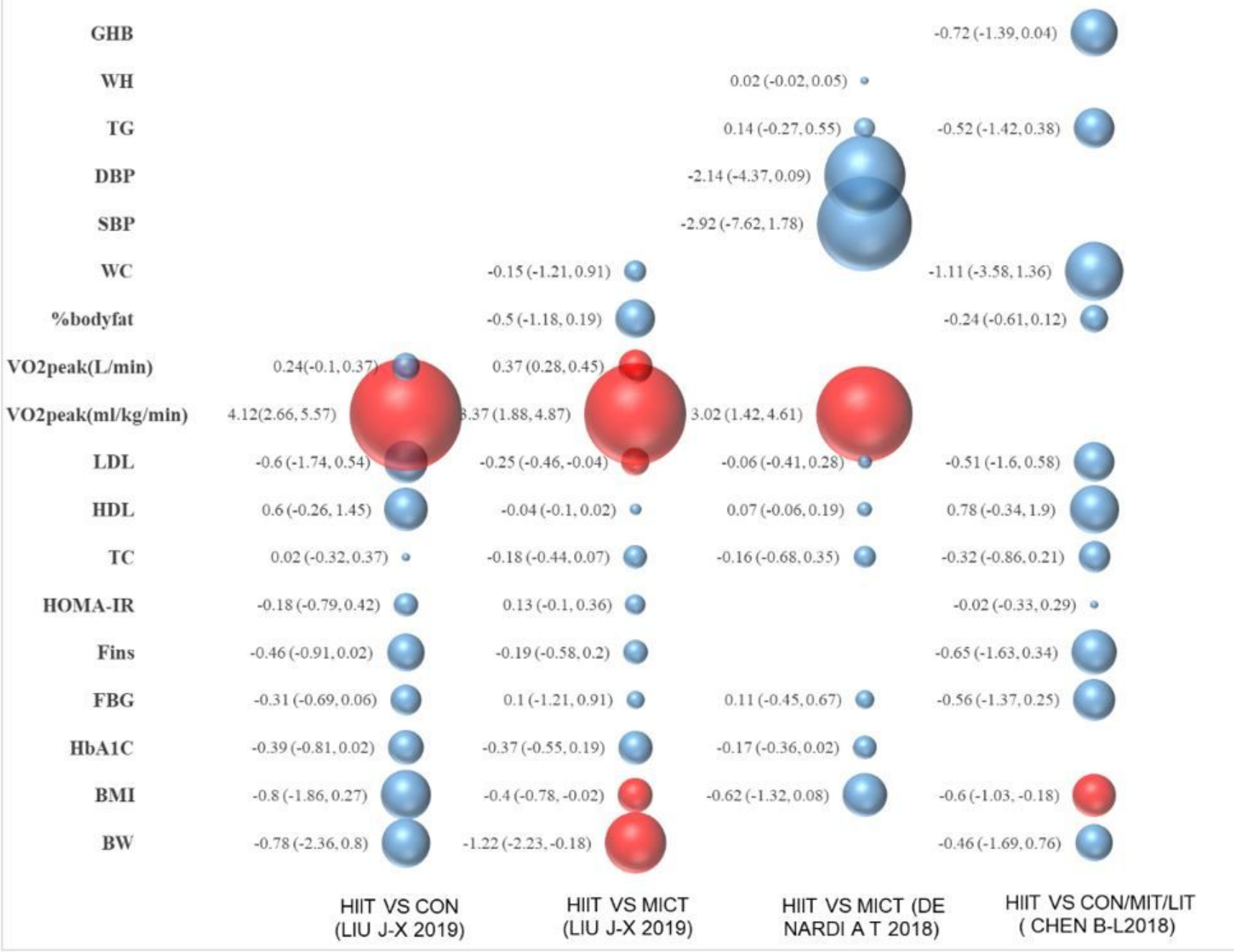

\section{Figure 4}

The visualization of evidence body of quantitative analysis

\section{Supplementary Files}

This is a list of supplementary files associated with this preprint. Click to download.

- TableS1Basiccharacteristicsofstudiesincluded.docx

- PRISMAChecklist.docx

- renamed52eb2.docx

- TableS2Excludedarticlesandreasonforexclusion.docx

- TableS3OriginalstudiesincludedinSRs.docx

- TableS4EvaluationresultsofAMSTAR2tools.docx

- TableS5EvaluationresultsofROBIStools.docx

- TableS6ResultsofqualityevaluationofGRADE.docx 